\title{
Capacidade combinatória para resistência à mancha branca em linhagens endogâmicas de milho
}

\author{
Paula de Souza Guimarães ${ }^{1}$, Maria Elisa Ayres Guidetti Zagatto Paterniani ${ }^{1}$, Christina Dudienas ${ }^{1}$, Reginaldo Roberto \\ Lüders ${ }^{1}$ e Paulo Boller Gallo ${ }^{2}$
}

\begin{abstract}
${ }^{1}$ Instituto Agronômico (IAC), Av. Barão de Itapura, n.1481, Caixa Postal 28, CEP: 13020-902, Campinas (SP). ${ }^{2}$ Pólo Regional de Desenvolvimento Tecnológico dos Agronegócios do Nordeste Paulista - APTA, Mococa - SP.

Autor para correspondência: Paula de Souza Guimarães (psguim@yahoo.com.br)

Data de chegada: 18/09/2007. Aceito para publicação em: 24/06/2009.
\end{abstract}

\section{RESUMO}

Guimarães, P.S.; Zagatto Paterniani, M.E.A.G.; Dudienas, C.; Lüders, R.R.; Gallo, P.B. Capacidade Combinatória para Resistência à Mancha Branca em Linhagens Endogâmicas de Milho. Summa Phytopathologica, v.35, n.4, p.282-287, 2009

Estimaram-se as capacidades geral (CGC) e específica (CEC) de combinação para resistência à mancha branca de 24 linhagens do programa de melhoramento de milho do IAC, de diferentes procedências, sob esquemas de dois dialelos parciais (Dialelo A e B), em Mococa, na região nordeste do Estado de São Paulo, na safra 2004/2005. O delineamento experimental utilizado foi o de blocos ao acaso com 3 repetições e 2 testemunhas comerciais (IAC 8333 e DKB 350). Avaliouse a severidade da mancha branca nas linhagens, nos 36 híbridos simples resultantes de cada dialelo parcial 6x6 e nos dois híbridos comerciais. A avaliação da doença foi realizada nos estádios de grãos leitosos a pastosos, através de escala de notas de 1 a 9 , correspondendo a $0 ; 1 ; 2,5 ; 5 ; 10 ; 25$; 50; 75 e mais de $75 \%$ de área foliar afetada. Houve diferenças significativas
$(\mathrm{P}<0,01)$ entre os híbridos para resistência à mancha branca, permitindo a discriminação dos híbridos experimentais. As linhagens mais resistentes foram PM518, IP4035 (Dialelo A) e IP398 (Dialelo B), enquanto que os híbridos IAC8333, PM 518 x IP4035 e IP701 x IP4035 no Dialelo A e L8 x IP398, VER266 x IP398 e L161 x IP398 no Dialelo B, mostraramse mais resistentes à doença. A análise dialélica mostrou efeitos significativos $(\mathrm{P}<0,01)$ para cruzamentos, CGC do Grupo I, CGC do Grupo II somente para o Dialelo A e CEC para resistência à mancha branca. Conclui-se, a partir da magnitude da CGC em relação à variação total, que a resistência à mancha branca tem natureza preponderantemente aditiva e que a presença de CEC significativa indica também a existência de efeitos de dominância.

Palavras-chave adicionais: resistência genética, dialelo, severidade, capacidade de combinação.

\section{ABSTRACT}

Guimarães, P.S.; Zagatto Paterniani, M.E.A.G.; Dudienas, C.; Lüders, R.R.; Gallo, P.B. Combining ability for resistance to white leaf spot of maize inbred lines. Summa Phytopathologica, v.35, n.4, p.282-287, 2009

Estimates of the general combining abilities (GCA) and specific combining abilities (SCA) of resistance to white leaf spot were obtained in 24 different IAC maize lines, following two partial diallel schemes (Dialelo A and Dialelo B), evaluated in Mococa, north-east region of the São Paulo State, in 2004/2005. The trials followed a randomized blocks design with three replicates and two commercial checks (IAC 8333 and DKB 350). The severity of white leaf spot were evaluated in the lines, in the 36 single cross hybrids results of two partial diallel $6 \times 6$ and in the two commercial hybrids. The disease was assessed according to a scale of notes from 1 to 9 , corresponding to: $0 ; 1 ; 2,5$; $5 ; 10 ; 25 ; 50 ; 75$ and $+75 \%$ affected leaf area in the adult plant,

Keywords: genetic resistance, diallel, severity, combining ability. respectively. There was significant difference $(\mathrm{P}<0.01)$ among the hybrids for resistance to white leaf spot, making possible discrimination of hybrids. The lines more resistance were PM518, IP4035 (Dialelo A) and IP398 (Dialelo B), while the hybrids IAC8333, PM $518 \times$ IP4035 and IP701 x IP4035 in the Dialelo A and L8 $x$ IP398, VER266 x IP398 and L161 x IP398 in the Dialelo B, showed more resistances to disease. The diallel analyses showed significant effects $(\mathrm{P}<0.01)$ for crosses, GCA in the set I, GCA in the set II, only for Dialelo A and SCA for resistance to white leaf spot. Based on the magnitude of GCA related to the total variation it was concluded that the resistence to white leaf spot is predominantly additive and significant SCA indicated dominance effects as well.
A mancha branca constitui-se numa das principais doenças da cultura do milho no Brasil, devido à generalidade e severidade com que ocorre em praticamente todas as regiões produtoras de milho.

A elevada intensidade da doença é um fator que vem contribuindo de forma marcante para a redução da produtividade de grãos na cultura do milho em genótipos suscetíveis, por isso a identificação de genótipos resistentes é uma necessidade indispensável em regiões de ocorrência do patógeno (13).

A mancha branca destaca-se pela sua ampla distribuição, devido ao grande número de cultivares suscetíveis encontrados. Essa doença é considerada de grande importância nas regiões tropicais e subtropicais do mundo onde se cultiva o milho e é particularmente bem adaptada a ambientes onde prevalece umidade elevada. No entanto, a resistência genética é a forma mais eficiente e econômica para controlar esta doença 
na cultura do milho, contribuindo para isso a disponibilidade de uma grande diversidade genética (3, 13 e 15).

Em 2001, Carson (4) relatou que a resistência à mancha branca possui característica quantitativa e que os genes com ação aditiva possuem grande importância hereditária, enquanto que genes com ação dominante têm menos importância na expressão. Paterniani et al., (13), Silva \& Moro (16), empregando dialelo, e Lüders (11) utilizando a metodologia de top cross entre linhagens de milho, corroboram estes resultados, obtendo evidências de que os efeitos predominantemente aditivos são responsáveis pela resistência à mancha branca, embora ocorram também efeitos de dominância. Posteriormente, Lopes et al., (10) estudando o controle genético da resistência à mancha branca em linhagens de milho sob condições de infecção natural da doença, verificaram que a variação genética devida a efeitos aditivos foi de 73 a $84 \%$, enquanto que, 13 a $23 \%$ foi devido aos efeitos dominantes, evidenciando a predominância dos efeitos gênicos aditivos sobre dominantes nas populações estudadas.

Entretanto, Amaral (2) estudando a base genética da resistência à mancha branca em milho, verificou que a ação gênica de dominância foi mais importante que os efeitos genéticos aditivos como fonte de variação para resistência a esta doença.

É importante ressaltar que em um programa de melhoramento visando à obtenção de híbridos com resistência genética à doença, é importante a escolha de germoplasma mais promissor, que apresente boas estimativas de heterose e de capacidade combinatória em cruzamentos entre linhagens, permitindo assim, determinar a contribuição de cada uma para a resistência, bem como para identificar combinações híbridas de interesse agronômico (12, 15 e 16).
O método de cruzamentos dialélicos permite a escolha dos parentais promissores com base principalmente nos conceitos de capacidade geral de combinação, capacidade específica de combinação e heterose (9). Em 1942, Sprague \& Tatum (17) propuseram os conceitos de capacidade geral e capacidade específica de combinação, relacionando-os, respectivamente, aos efeitos gênicos aditivos e não aditivos (dominantes e epistáticos).

Segundo Ferreira et al., (7), a capacidade geral de combinação (CGC) está relacionada a efeitos aditivos, mostrando o comportamento médio dos pais em combinações híbridas, enquanto que a capacidade específica de combinação (CEC) está relacionada a efeitos gênicos não-aditivos, caracterizando os desvios de combinações híbridas em relação ao comportamento médio dos pais.

Neste contexto, o presente trabalho teve por objetivos avaliar a capacidade de combinação para resistência à mancha branca em 12 linhagens do programa de melhoramento de milho do IAC, de diferentes procedências, visando fornecer subsídios para o desenvolvimento de variedades e híbridos resistentes ao agente causal da mancha branca.

\section{MATERIAL E MÉTODOS}

As 24 linhagens utilizadas nos cruzamentos no presente trabalho pertencem ao banco de germoplasma do Instituto Agronômico (IAC) e distinguem-se em dois grandes grupos: linhagens antigas do programa de melhoramento de milho e linhagens recentes, provenientes do Centro Internacional de Melhoramento de Milho e Trigo (CIMMYT) (Tabela 1). Estas linhagens foram cruzadas em dois dialelos parciais 6x6.

Tabela 1. Características das linhagens utilizadas nos dialelos parciais.

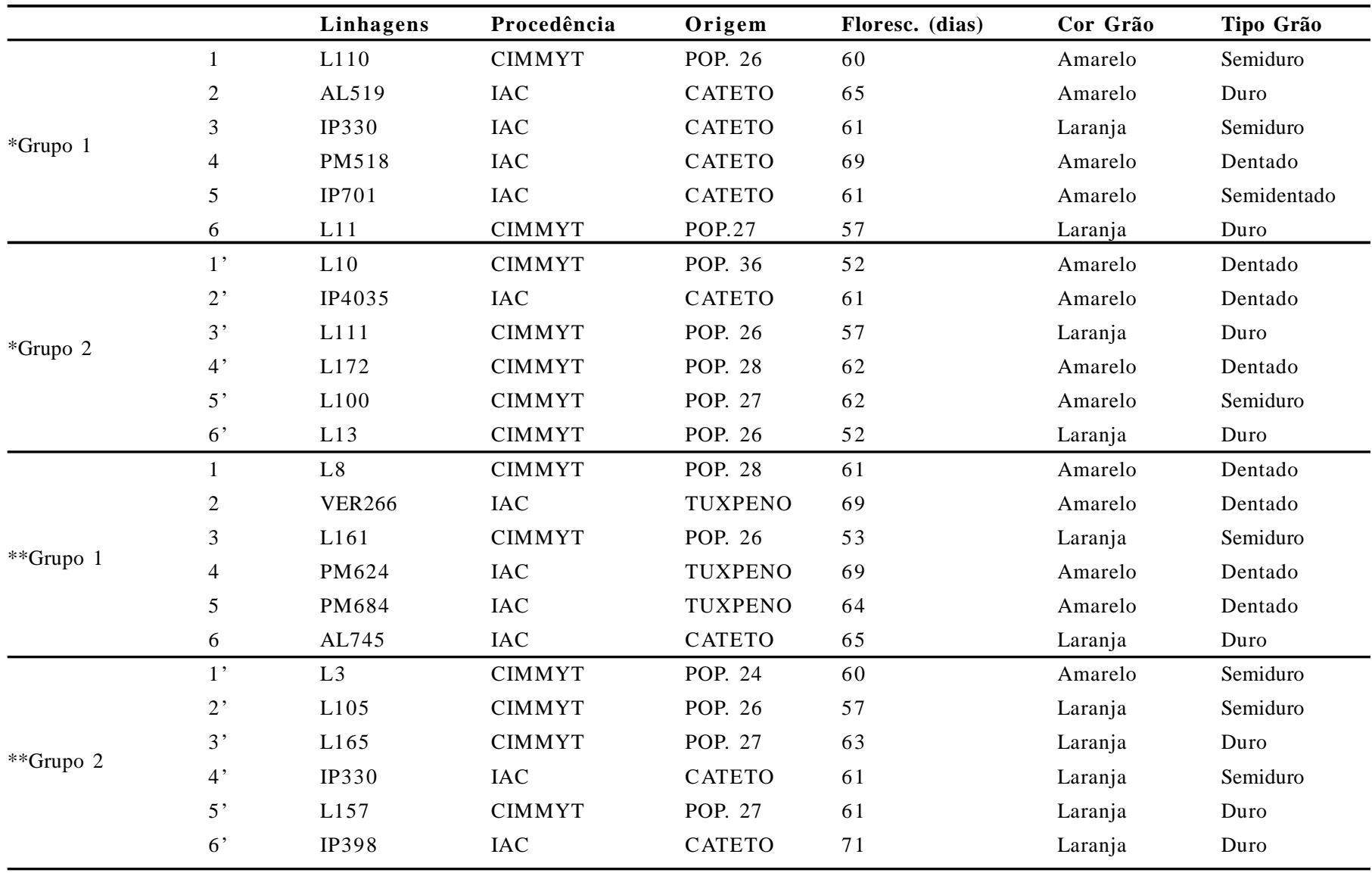

(*) Dialelo parcial A

(**) Dialelo parcial B 
Os 36 híbridos simples resultantes de cada dialelo parcial 6 × 6 e os dois híbridos comerciais foram avaliados no Pólo Regional de Desenvolvimento Tecnológico dos Agronegócios do Nordeste Paulista - APTA em Mococa - SP, na safra 2004/2005.
O delineamento experimental utilizado foi o de blocos ao acaso com três repetições e duas testemunhas comerciais (IAC 8333 e DKB 350). Cada parcela foi constituída por duas linhas de 5 m espaçadas de $0,90 \mathrm{~m}$ entre linhas e de 0,20 m entre plantas, com um total de 50 plantas.

Tabela 2. Valores de severidade de mancha branca (MB) nos Dialelos A e B, em experimento realizado em Mococa (SP), safra $2004 / 2005$.

\begin{tabular}{|c|c|c|c|c|c|c|}
\hline \multirow[b]{2}{*}{ HS } & \multirow[b]{2}{*}{ Origem } & \multicolumn{2}{|c|}{ Dialelo A } & \multirow[b]{2}{*}{ Origem } & \multicolumn{2}{|c|}{ Dialelo B } \\
\hline & & Médias transf. ${ }^{(1)}$ & Médias originais & & Médias transf. & Médias originais \\
\hline $1 \times 1^{\prime}$ & L110 X L10 & $2,88 \mathrm{a}-\mathrm{c}$ & 7,29 & L8 X L3 & $2,95 \mathrm{a}$ & 7,70 \\
\hline $1 \times 2^{\prime}$ & L110 X IP4035 & 2,66 a-f & 5,66 & L8 X L105 & $2,50 \mathrm{a}-\mathrm{d}$ & 5,25 \\
\hline $1 \times 3^{\prime}$ & L110 X L111 & 2,88 a-d & 6,90 & L8 X L165 & 2,66 a-d & 5,66 \\
\hline $1 \times 5^{\prime}$ & L110 X L100 & $3,02 \mathrm{a}$ & 8,12 & L8 X V157 & $2,81 \mathrm{ab}$ & 6,90 \\
\hline $1 \times 6^{\prime}$ & L110 X L13 & $2,70 \mathrm{a}-\mathrm{e}$ & 6,45 & L8 X IP398 & $2,02 \mathrm{~cd}$ & 3,08 \\
\hline $2 \times 1^{\prime}$ & AL519 X L10 & $2,50 \mathrm{~b}-\mathrm{g}$ & 5,25 & VER266 X L3 & $2,95 \mathrm{a}$ & 7,70 \\
\hline $2 \times 2^{\prime}$ & AL519 X IP4035 & $2,23 \mathrm{f}-\mathrm{h}$ & 3,97 & VER266 X L105 & $2,41 \mathrm{a}-\mathrm{d}$ & 4,81 \\
\hline $2 \times 3^{\prime}$ & AL519 X L111 & $2,23 \mathrm{f}-\mathrm{h}$ & 3,97 & VER266 X L165 & $2,88 \mathrm{ab}$ & 7,29 \\
\hline $3 \times 1^{\prime}$ & IP330 X L10 & 2,66 a-f & 5,66 & L161 X L3 & $2,88 \mathrm{ab}$ & 7,29 \\
\hline $3 \times 2^{\prime}$ & IP330 X IP4035 & $2,23 \mathrm{f}-\mathrm{h}$ & 3,97 & L161 X L105 & $2,74 \mathrm{a}-\mathrm{c}$ & 6,51 \\
\hline $3 \times 3^{\prime}$ & IP330 X L111 & $2,50 \mathrm{~b}-\mathrm{g}$ & 5,25 & L161 X L165 & $2,95 \mathrm{a}$ & 7,70 \\
\hline $3 \times 4^{\prime}$ & IP330 X L172 & $2,41 \mathrm{~d}-\mathrm{h}$ & 4,81 & L161 X IP330 & $2,74 \mathrm{a}-\mathrm{c}$ & 6,51 \\
\hline $3 \times 5^{\prime}$ & IP330 X L100 & $2,95 \mathrm{ab}$ & 7,70 & L161 X L157 & $2,95 \mathrm{a}$ & 7,70 \\
\hline $3 \times 6^{\prime}$ & IP330 X L13 & 2,32 e-h & 4,38 & L161 X IP398 & $1,91 \mathrm{~d}$ & 2,68 \\
\hline $4 \times 1^{\prime}$ & PM518 X L10 & $2,12 \mathrm{gh}$ & 3,49 & PM624 X L3 & $2,95 \mathrm{a}$ & 7,70 \\
\hline $4 \times 2^{\prime}$ & PM518 X IP4035 & $2,02 \mathrm{~h}$ & 3,08 & PM624 X L105 & 2,49 a-d & 5,20 \\
\hline $4 \times 3^{\prime}$ & PM518 X L111 & $2,41 \mathrm{~d}-\mathrm{h}$ & 4,81 & PM624 X L165 & $2,80 \mathrm{ab}$ & 6,84 \\
\hline $4 \times 4^{\prime}$ & PM518 X L172 & $2,23 \mathrm{f}-\mathrm{h}$ & 3,97 & PM624 X IP330 & $2,32 a-d$ & 4,38 \\
\hline $5 \times 5^{\prime}$ & IP701 X L100 & $2,80 a-d$ & 6,84 & PM684 X L157 & $2,81 \mathrm{ab}$ & 6,90 \\
\hline $5 \times 6^{\prime}$ & IP701 X L13 & $2,50 \mathrm{~b}-\mathrm{g}$ & 5,25 & PM684 X IP398 & $2,21 \mathrm{a}-\mathrm{d}$ & 3,96 \\
\hline $6 \times 1^{\prime}$ & L11 X L10 & $2,61 \mathrm{a}-\mathrm{d}$ & 6,90 & AL745 X L3 & $2,81 \mathrm{ab}$ & 6,90 \\
\hline $6 \times 2^{\prime}$ & L11 X IP4035 & $2,49 \mathrm{c}-\mathrm{g}$ & 5,20 & AL745 X L105 & 2,57 a-d & 6,78 \\
\hline $6 \times 3^{\prime}$ & L11 X L111 & 2,74 a-e & 6,51 & AL745 X L165 & $2,88 \mathrm{ab}$ & 7,29 \\
\hline $6 \times 4^{\prime}$ & L11 X L172 & $2,95 \mathrm{ab}$ & 7,70 & AL745 X IP330 & 2,41 a-d & 4,81 \\
\hline $6 \times 5^{\prime}$ & L11 X L100 & $2,88 \mathrm{a}-\mathrm{c}$ & 7,29 & AL745 X L157 & 2,41 a-d & 4,81 \\
\hline \multirow[t]{3}{*}{$6 \times 6$} & L11 X L13 & $2,32 \mathrm{e}-\mathrm{h}$ & 4,38 & AL745 X IP398 & 2,21 a-d & 3,96 \\
\hline & DKB 350 & $2,41 \mathrm{~d}-\mathrm{h}$ & 4,81 & DKB 350 & 2,32 a-d & 4,38 \\
\hline & IAC 8333 & $2,02 \mathrm{~h}$ & 3,08 & IAC 8333 & 2,21 a-d & 3,96 \\
\hline Média & & 2,51 & & & 2,50 & \\
\hline Dms & & 0,433 & & & 0,777 & \\
\hline CV\% & & 5,2 & & & 9,3 & \\
\hline
\end{tabular}

(1) Dados transformados em " $x+1$ ".

Médias com letras diferentes na coluna diferem a 5\% pelo Teste de Duncan. 
Avaliou-se a severidade da mancha branca no dialelo parcial segundo o procedimento do Guia Agroceres de Sanidade (1). A avaliação da doença foi efetuada no estádio de grãos leitosos a pastosos utilizando-se escala de notas de 1 a 9 para $0 ; 1 ; 2,5 ; 5 ; 10 ; 25 ; 50 ; 75$ e mais de $75 \%$ de área foliar afetada, respectivamente. As notas médias de severidade da doença foram transformadas em raiz de " $x+1$ " e submetidas a análises da variância e a Teste de Duncan para comparação de médias dos tratamentos.

Notas de 1 a 3 - genótipos resistentes; 4 a 6 - genótipos moderadamente suscetíveis; 7 a 8 - genótipos suscetíveis e 9 - genótipo altamente suscetível.

Para análise genética e obtenção da capacidade de combinação das linhagens, foi utilizado o programa Genes (5), adotando-se a adaptação do modelo 4 de Griffing (8 e 9) descrita por Cruz \& Regazzi (6):

Tabela 3. Quadrados médios da análise de variância dialélica quanto à resistência a mancha branca de 36 híbridos simples experimentais de milho resultantes dos Dialelos A e B, em experimento realizado em Mococa (SP), safra 2004/2005.

\begin{tabular}{llcl}
\hline \multirow{2}{*}{ F.V. } & \multirow{2}{*}{ G.L. } & \multicolumn{2}{c}{ Quadrados Médios MB } \\
\cline { 3 - 4 } Cruzamentos & 35 & $0,240^{* *}$ & Dialelo B \\
CGC G-1 & 5 & $0,743^{* *}$ & $0,275^{* *}$ \\
CGC G-2 & 5 & $0,597^{* *}$ & 0,090 \\
CEC 1x2 & 25 & $0,068^{* *}$ & $0,071^{* *}$ \\
Resíduo & 70 & 0,017 & 0,051 \\
Média: & & 2,529 & 2,557 \\
DP (u): & & 0,013 & 0,022 \\
\hline
\end{tabular}

**: significativo a $1 \%$ pelo Teste $\mathrm{F}$.

MB: variável resistência à mancha branca.

Tabela 4. Estimativa dos efeitos da capacidade geral de combinação $\left(\hat{\mathbf{g}}_{\mathbf{i}}\right)$ de 12 linhagens de milho do Dialelo $\mathrm{A}$ e do Dialelo $\mathrm{B}$, quanto à resistência a mancha branca (MB), em experimento realizado em Mococa (SP), safra $2004 / 2005$.

\begin{tabular}{|c|c|c|c|}
\hline & & $\hat{\mathrm{g}}_{\mathrm{i}}$ & \\
\hline \multirow{2}{*}{ Linhagem } & Dialelo A & \multirow{2}{*}{ Linhagem } & Dialelo B \\
\hline & MB & & MB \\
\hline Grupo 1 & & Grupo 1 & \\
\hline $1 \mathrm{~L} 110$ & 0,260 & $1 \mathrm{~L} 8$ & 0,001 \\
\hline 2 AL519 & $-0,079$ & 2 VER266 & $-0,053$ \\
\hline 3 IP330 & $-0,051$ & 3 L161 & 0,138 \\
\hline 4 PM518 & $-0,329$ & 4 PM624 & $-0,046$ \\
\hline 5 IP701 & 0,066 & 5 PM684 & $-0,027$ \\
\hline 6 L11 & 0,132 & 6 AL745 & $-0,012$ \\
\hline
\end{tabular}

\begin{tabular}{lllc} 
Grupo 2 & \multicolumn{3}{c}{ Grupo 2 } \\
1' L10 & 0,082 & 1' L3 & 0,300 \\
2' IP4035 & $-0,289$ & 2' L105 & $-0,022$ \\
3' L111 & 0,004 & 3' V165 & 0,235 \\
4' L172 & 0,077 & 4' IP330 & $-0,096$ \\
5' L100 & 0,238 & 5' L157 & 0,081 \\
6' L13 & $-0,112$ & 6' IP398 & $-0,497$ \\
\hline DP $\left(\hat{\mathbf{g}}_{\mathbf{i}}\right):$ & 0,028 & DP $(\mathrm{Gj}):$ & 0,049 \\
\hline
\end{tabular}

DP: desvio padrão da estimativa da CGC

MB: variável resistência à mancha branca.
$\mathrm{Y}_{\mathrm{ij}}=\mathrm{m}+\mathrm{g}_{\mathrm{i}}+\mathrm{g}_{\mathrm{j}}+\mathrm{s}_{\mathrm{ij}}+\varepsilon_{\mathrm{ij}}$ onde:

$\mathrm{Y}_{\mathrm{ij}}$ : é a média do híbrido simples entre o i-ésimo progenitor do grupo 1 e j-ésimo progenitor do grupo 2 nas $r$ repetições

m: é a média geral

$\mathrm{g}_{\mathrm{i}}$ : é o efeito da capacidade geral de combinação do i-ésimo progenitor do grupo 1

$\mathrm{g}_{\mathrm{j}}$ : é o efeito da capacidade geral de combinação do j-ésimo progenitor do grupo 2

$\mathrm{s}_{\mathrm{ij}}$ : é o efeito da capacidade específica de combinação entre as linhagens de ordem i e j dos grupos 1 e 2 , respectivamente

$\varepsilon_{\mathrm{ij}}$ : é o erro experimental médio.

\section{RESULTADOS E DISCUSSÃO}

Houve diferença significativa $(\mathrm{P}<0,01)$ entre os híbridos no ensaio quanto à resistência à mancha branca, permitindo a discriminação dos híbridos e mostrando que ocorreu variabilidade entre as 12 linhagens de cada Dialelo para a reação ao patógeno.

Os híbridos mais resistentes no Dialelo A foram o IAC8333, 4x2' (PM 518 x IP4035) e 5x2' (IP701 x IP4035), com nota 3,08 (2,5\% de área foliar afetada). Destacaram-se ainda, com notas próximas a 4 correspondendo a, aproximadamente, $5 \%$ de área foliar afetada (moderadamente resistentes), os híbridos: 2x2' (AL519 x IP4035), 2x3' (AL519 x L111), 3x2' (IP330 x IP4035), 3x6' (IP330 x L13), 4x1' (PM518 x L10), 4x4' (PM518 x L172), 4x5' (PM518 x L100) e 4x6' (PM518 x L13) (Tabela 2).

No experimento Dialelo B (Tabela 2), foram considerados mais resistentes os híbridos 1x6' (L8 x IP398), 2x6' (VER266 x IP398) e 3x6' (L161 x IP398) com notas médias de 2,68 a 3,08, correspondendo a 2,5\% da área foliar afetada. O híbrido 4x6' (PM624 x IP398) foi considerado moderadamente resistente, pois obteve nota média de 3,49 , o que correspondendo a quase $5 \%$ da área foliar afetada.

Na Tabela 3 está apresentada a análise de variância dialélica para os dois Dialelos. No Dialelo A, observaram-se à ocorrência de efeitos significativos de capacidade geral de combinação (CGC) dos Grupos 1 e 2 e também de capacidade específica de combinação (CEC), praticamente na mesma magnitude dos quadrados médios, confirmandose vários trabalhos da literatura que concluíram que a resistência à mancha branca tem caráter quantitativo (11, 13 e 15). Alguns trabalhos mostram a importância do efeito de aditividade na herança da resistência à mancha branca $(10,11,13,14$ e 16), embora a participação da dominância também seja pronunciada ou até mais importante (2), sendo a resistência à doença no presente trabalho determinada por efeitos aditivos e de dominância como fonte de variação para a resistência a doença.

No Dialelo B, observaram efeitos significativos $(\mathrm{P}<0,01)$ de cruzamentos e de CGC somente para o Grupo 2, indicando que as linhagens do Grupo 2 não contribuíram com efeitos aditivos para a resistência à mancha branca, quando em cruzamentos visando à obtenção de híbridos experimentais.

Estimativas médias da CGC, para as 24 linhagens avaliadas, nos dois experimentos, são apresentadas na Tabela 4. Metade das linhagens apresentou efeitos de CGC negativos, indicando que, na média, esses parentais contribuíram para aumentar a resistência em cruzamentos. Verificou-se a existência de fontes de resistência à mancha branca nas linhagens PM518 (Grupo 1) e IP4035 (Grupo 2) do Dialelo A, as quais apresentaram os maiores efeitos negativos de CGC, enquanto que no Dialelo B, a linhagem que se destacou foi a IP398 do Grupo 2. 
Tabela 5. Estimativas dos efeitos da capacidade específica de combinação $\left(\hat{\mathrm{S}}_{\mathrm{ij}}\right)$ resultantes do cruzamento de linhagens de milho do Dialelo A quanto à resistência a mancha branca no experimento realizado em Mococa (SP), safra 2004/2005.

\begin{tabular}{|c|c|c|c|c|c|c|}
\hline Linhagem & 1' L10 & 2' IP4035 & 3' L111 & 4' L172 & 5' L100 & 6' L13 \\
\hline \multicolumn{7}{|c|}{$\hat{\mathbf{s}}_{\mathbf{i j}}$} \\
\hline $1 \mathrm{L110}$ & $-0,038$ & 0,068 & $-0,026$ & 0,034 & $-0,060$ & 0,023 \\
\hline 3 IP330 & 0,007 & 0,012 & 0,018 & $-0,155$ & 0,184 & $-0,066$ \\
\hline 4 PM518 & $-0,182$ & 0,090 & 0,195 & $-0,077$ & $-0,138$ & 0,112 \\
\hline 5 IP701 & 0,223 & $-0,305$ & 0,034 & 0,096 & $-0,065$ & 0,018 \\
\hline$\overline{\mathrm{DP}}\left(\mathrm{s}_{\mathrm{ij}}\right):$ & 0,063 & & & & & \\
\hline
\end{tabular}

DP: desvio padrão da estimativa da CEC.

Tabela 6 - Estimativas dos efeitos da capacidade específica de combinação $\left(\hat{\mathrm{S}}_{\mathrm{ij}}\right)$ resultantes do cruzamento de linhagens de milho do Dialelo B quanto à resistência a mancha branca no experimento realizado em Mococa (SP), safra 2004/2005.

\begin{tabular}{|c|c|c|c|c|c|c|}
\hline Linhagem & 1' L3 & 2' L105 & 3' L165 & 4' IP330 & 5' L157 & 6' IP398 \\
\hline \multicolumn{7}{|c|}{$\hat{\mathbf{s}}_{\mathbf{i j}}$} \\
\hline $1 \mathrm{L8}$ & 0,092 & $-0,036$ & $-0,133$ & $-0,051$ & 0,171 & $-0,044$ \\
\hline 3 L161 & $-0,115$ & 0,067 & 0,020 & 0,142 & 0,174 & $-0,288$ \\
\hline 4 РM624 & 0,139 & 0,001 & 0,054 & $-0,094$ & $-0,209$ & 0,109 \\
\hline$\overline{D P}\left(s_{i j}\right):$ & 0,109 & & & & & \\
\hline
\end{tabular}

DP: desvio padrão da estimativa da CEC.

O maior efeito da CEC negativa no Dialelo A, para a avaliação da severidade da doença na planta, foi observado entre os cruzamentos: 2x3' (AL519 x L111), 3x4' (IP330 x L172), 4x1' (PM518 x L10), 4x5' (PM518 x L100), 5x2' (IP701 x IP4035) e 6x6' (L11 x L13) (Tabela 5). Já para o Dialelo B (Tabela 6), os maiores efeitos negativos da CEC foram observados nos seguintes híbridos experimentais: 1x3' (L8 x L165), 2x5' (VER266 x L157), 3x1' (L161 x L3), 3x6' (L161 x IP398), 4x5' (PM624 x L157), 5x3' (PM684 x L165) e 6x5' (AL745 x L157), mostrando que os devidos cruzamentos entre as linhagens endogâmicas foram eficientes para a formação de genótipos com maior resistência ao patógeno.

Estes resultados comprovam a existência de fontes de resistência à mancha branca nas linhagens PM518, IP4035 e IP398, que podem ser utilizadas em programas de obtenção de híbridos ou de seleção recorrente para melhoramento de populações.

\section{AGRADECIMENTOS}

À FAPESP - pelo financiamento do projeto.

\section{REFERÊNCIAS BIBLIOGRÁFICAS}

1. Agroceres. Guia de sanidade. 2.ed. São Paulo: Sementes Agroceres, 1996. $72 \mathrm{p}$.

2. Amaral, A.L. do. Etiologia e genética da resistência à mancha branca do milho. Porto Alegre: Universidade Federal do Rio Gran- de do Sul. 2005. 93f. Tese (Doutorado em Fitotecnia). Universidade Federal do Rio Grande do Sul, Porto Alegre, 2005.

3. Balmer, E.; Pereira, O.A.P. Doenças do milho. In: Paterniani, E.; Viegas, G.P. (Ed.) Melhoramento e produção de milho. 2.ed. Campinas: Fundação Cargill, v.2, cap.14, p.595-634, 1987.

4. Carson, M.L. Inheritance of resistance to Phaeosphaeria leaf spot of maize. Plant Disease, Cornell University press, v.85, p.798-800, 2001.

5. Cruz, C.D.; Aplicativo computacional em Genética e Estatística: programa genes. Viçosa. UFV, 1997. $442 \mathrm{p}$.

6. Cruz, C.D. \& Regazzi, A.J. Modelos biométricos aplicados ao melhoramento genético. Viçosa, UFV, 1997. 380p.

7. Ferreira, M.A.J. da F.; Braz, L.T.; Queiroz, M.A. de; ChurataMasca, M.G.C.; Vencovsky, R. Capacidade de combinação em sete populações de melancia. Pesquisa Agropecuária Brasileira, Brasília, v.37, p.968-970, 2002.

8. Griffing, J.B. A generalized treatment of the use of diallel crosses in quantitative inheritance. Heredity, The Genetical Society of Great Britain, v.10, p. 31-50, 1956a.

9. Griffing, J.B. Concept of general and specific combining ability in relation to diallel systems. Australian Journal of Biological Science, Melbourne, v.9, p. 463-493, 1956b.

10. Lopes, M.T.G.; Lopes, R.; Brunelli, K.R.; Pereira da Silva, H.; Matiello, R.R. e Camargo, L.E.A. Controle genético da resistência à mancha-de-Phaeosphaeria em milho. Ciência Rural, v.37, n.3, p.605-611, 2007.

11. Lüders, R.R. Desempenho de Linhagens de Milho (Zea mays L.) em Top Crosses com Testadores de Base Genética Restrita e Avaliação de Híbridos Triplos. Dissertação (Mestrado em Agricultura Tropical e Subtropical). Instituto Agronômico (IAC), Campinas, 2003.

12. Melo, W.M.C.; Pinho, R.G.V.; Ferreira, D.F. Capacidade combinatória e divergência genética em híbridos comerciais de milho. 
Ciência Agrotécnica, Lavras, v.25, n.4, p.821-830, 2001.

13. Paterniani, M.E.A.G.Z.; Sawazaki, E.; Dudienas, C.; Pereira, J.C.V.N.A. Cruzamentos dialélicos de linhagens de milho sob condições de mancha de Phaeosphaeria. Scientia Agricola, Piracicaba, v.57, n.2, p.313-318, 2000.

14. Silva, H.P. Genética da resistência a Phaeosphaeria maydis em milho. Jaboticabal: Universidade Estadual Paulista, 2002. 105f.

Tese (Doutorado). Faculdade de Ciências Agrárias e Veterinárias,

Universidade Estadual Paulista, Jaboticabal, 2002.

15. Silva, H.P.; Barbosa, M.P.M.; Nass, L.L.; Camargo, L.E.A. Capa- cidade de Combinação e Heterose para Resistência a Puccinia polysora Underw. em Milho. Scientia Agricola, Piracicaba, v.58, n.4, p.777-783, 2001.

16. Silva, H.P. \& Moro, J.R. Diallel analysis of maize resistance to Phaeosphaeria maydis. Scientia Agricola, Piracicaba, v.61, n.1, p.36-42, 2004.

17. Sprague, G.F., Tatum, L.A. General vs. specific combining ability in single crosses of corn. Journal American Society of Agronomy, Madison, v. 34, p. 923-932, 1942. 